\section{Minority Report e a gestão do futuro}

\section{RESUMO}

Partindo da alegoria de Steven Spielberg em seu filme Minority Report, procuramos abordar a nova faceta do arranjo razão de estado \& mídia na composição de uma cidade planetária pós-moderna, hiperindividualizada pela lógica do consumo de imagens e sentidos, e problematizamos os compostos subjetivos que parecem emergir neste cenário.

\section{ABSTRACT}

Starting from the allegory in Steven Spielberg's film, Minority Report, we endeavour in this article to discuss the new facet of the arrangement reason of State $\&$ media in the composition of a postmodern planetary city, hyperin-dividualized by the logic of the consumption of images and senses; and we problematize the subjective composites which seem to emerg in this scenario.

\section{PALAVRAS-CHAVE (KEY WORDS)}

- Minority Report

- Cidade (City)

- Pós-modernidade (Postmodernity)
O ANO QUe ESTAmos é o de 2054. Por ora, apenas isto como pista. Logo saberemos que se trata de uma fábula futurista. É Steven Spielberg quem a assina. Vivemos numa Washington sem crimes, sem assassinatos, sem estupros, quem sabe, sem qualquer mendicância (mas não é disto que se trata... ou o que importa), ou ainda - eis o mapa cartográfico da cidade, e quem sabe se a cidade é desprovida dos guetos comunais da era do pós-guerra (compacto, marcadamente confinado, atravessado pela completa divisão racial, e uma outra, a divisão social do trabalho - isto aqueles guetos, ou seu modus vivendi), ou ainda, quem sabe, o que a caracterize sejam os hiperguetos dos anos 1980 e 1990, marcados estes pela noção de underclass, status conferido pela produção simbólica que lhe é exterior desde sempre - "jornalistas, políticos, acadêmicos e peritos do governo - para fins de controle e disciplinamento" (Wacquant, 2001, p.50). Outra vez, ousamos dizer, não é disto que se trata, ou que importa. Ao menos à peça cinematográfica de Spielberg, não é isto o que importa. Aquilo de que se trata é uma inexistência a que se alça, isto no filme: a de que não haja mais crimes, a de que a violência social fora contida, desde logo e sempre, por um programa especial de governo. Questões que digam respeito aos consumidores zerados se estes houver, à marginalia de exclusão se esta insistir em haver, ou aos supranumerários que se encerram nos bunkers que é já a cidade numa sua parcela, escapam ao escopo da produção hollywoodiana, ou à aludida raison d'être do Estado pós-moderno que, aqui, diz da América a sua condição. $\mathrm{O}$ ano é o de 2054. A cidade está limpa de uma vez por todas, embora persista a inquietude que atravessa as falas dos personagens, qual seja, a que diz respeito ao que seriam as possíveis falhas do sistema - será que 
existem falhas no sistema? Mas qual o sistema? Spielberg fabula: O programa especial do pré-crime que remete às funções do departamento de polícia da capital americana. E já não poderíamos seguir as pistas de Loic Wacquant ao falar do Estado carcerário norte-americano, o seu rigor penal, a sua tolerância zero, a difusão publicitária de seus feitos, e o recolhimento massivo dos "precários, estrangeiros, drogados", os "clientes" privilegiados no grande enclausuramento neoliberal. Loic Wacquant cartografa o presente que experimentamos - o da sociedade comunicacional pós-fordista, anos 80 e 90, este que somos, na curva irremediável do État Providence em seus dispositivos sociais. Spielberg fabula um futuro não tão distante - um tanto já aqui, na virtualização do espaço político, na desconstrução da esfera pública, no desmantelamento do social, e na investidura contumaz das novas tecnologias como condição mesma de problematização das modalidades vigentes de produção subjetiva. O que é dizer: entre o presente que somos \& que já experimentamos em seu ocaso, e a fábula que diz de nós o que não realizamos \& que já nos deposita no raio de uma sua racionalidade possível - quem sabe possamos dizer que haja uma quase continuidade. Entre o mapa do real de Wacquant e o fabulário sem terra de Spielberg parece insistir um rasto, um traçado equívoco e sugestivo, um plano de imanência comum em que os problemas e suas resoluções impõem um solo único, uma comunidade de motivações e princípios, e também, aqui e ali, uma radicalização de postura e posição, ou já uma teleologia afirmada, como se o futuro realizasse o que já vislumbramos em ocorrência entre nós, a hiperinflação das narrativas sobre a violência como sendo aquilo de que se trata de pensar quando se diz do Estado a sua razão de ser, e quando se diz do governo a sua razão política. Mas vejamos qual é esta quase continuidade a que aludimos. Depositaremos tudo, digo a esta alusão, no problema do Estado e de seu procedimento, e a questão é apenas uma: o que se trata quando se pensa governar?

Paul Veyne, em seu famoso ensaio sobre Michel Foucault, intitulado Foucault revoluciona a história, nos mostrou o procedimento habitual do pensador francês, o pensar a descontinuidade lá onde buscávamos evoluções e progressos como mote das realizações e dos fatos humanos, ou a raridade que é já dizer do vazio instalado em torno destes fatos humanos e que indica do saber em seus extratos aquilo que já dele dista, a diferença inscrita como condição de alteridade. É disto o quadro que ele supõe: a passagem de uma forma a outra de razão de Estado, a arte do governo em seu conjunto de práticas. A questão que ele se propõe: Por que é que se dá a suspensão da gladiatura comum à Roma pagã durante o período cristão? Desde logo dizemos: a falsa questão seria buscarmos nas hipóteses que falam de uma humanização do governo, ou nas que sugerem o combate entre gladiadores como contra-senso ante os preceitos religiosos da Roma Cristã, a condição da passagem. Veyne supõe um outro, a saber: uma nova economia política do poder. Nas suas palavras: "É preciso desviarse de 'a' política, para distinguir uma forma rara, um bibelô político de época cujos arabescos inesperados constituem a chave do enigma. (...) É preciso desviar os olhos dos objetos naturais para perceber uma certa prática, muito bem datada, que os objetivou sob um aspecto datado como ela" (1995, p. 154). Tal olhar, ou tal foco, pressupondo a mira obstinada na parte oculta do iceberg político - o dizer o que, por vezes, escapa ao visível, mas que é condição de toda visibilidade, ou o quase transcendental, o transcendental-histórico, como condição de ser daquilo que há. Aqui se trata de pensar a arte do governar e sua racionalidade, e Veyne indica a direção da encetada foucaulteana - em lugar do objeto natural a que atenderia pelo nome de 'governados', e em lugar do objeto natural 'a política', a cartografia de Foucault impõe algo distinto, um certo seu nominalismo, ou seja, em lugar de objetos naturais, práticas mui bem 
datadas, mui bem situadas - não 'a política' mas 'uma' certa política, não mais 'os governados' mas aquilo a que se dá uma certa política, ou seja, 'uma' população. E então, entre o governo da Roma Pagã e o da Roma Cristã, e entre os governados de uma e outra, o que passamos a ter é da ordem de uma multiplicidade distinta, cada qual indicando uma certa relação de pertença que certamente exclui a outra, ou que certamente sugere a esta outra excluída um seu lugar, agora, o da incongruência. Da suspensão da gladiatura o que diríamos seria a remissão deste desaparecimento aos cálculos mesmos de um poder que não mais se pretende fáustico, espetaculoso, majestoso, em que a palavra do soberano implica a condição de vida \& morte dos súditos, matar ou deixar viver, como na peça Calígula, de Albert Camus, em que o imperador romano rasga o decreto de morte de um palaciano para fazer ver o quão corresponde ao seu timbre \& força a divinatio, sua proveniência divina, seu lugar de exceção, o seu dispor da vida \& da morte como matéria e extensão do que ele pode, a sua força e potência. Não mais fáustico o poder, mas outro o seu cálculo e regime, aqui e agora, minucioso, imiscuindo-se em filamentos mínimos, edípico, familial. Não mais Calígula, mas Édipo, e este sendo não aquele que não sabe, mas aquele que tudo quer saber, que tudo quer dispor, ao que ele se dá à busca, à investigação contumaz e rigorosa, à vasculhada das partes e do todo. No outro lado do poder, não mais a massa indistinta de quem se cobra impostos de forma indiscriminada, mas a população como alvo dos cuidados do poder que tornam a vida a ínfima matéria em que seus esforços de gestão se debruçam ${ }^{1}$. O monarca agora é papai na gestão do povocriança - quer cuidar da vida de todos, maximizá-la, torná-la otimizada, sobreinvestila de uma positividade em que o que dela se arranja é de imediato atravessado por fluxos de extração de mais-valia política, econômica, disciplinar. Não se tratará mais de matar ou deixar viver para fazer funcionar o poder, mas o poder funciona na medida mesma em que faz viver uma vida asseptizada, regulada e obreira. E Veyne dirá: "(...) a isso se chama welfare state, e nele vivemos" (ibid, p. 155). Ou vivíamos num ainda há pouco. Estamos agora às portas do ano 2006, e a janela que nos damos ao vislumbre e contemplação indica já outra data, não esqueçamos, a do fabulário de Spielberg, o ano de 2054.

Àquela questão-vetor a que nos propusemos, a inquirição pela vontade de governo, a formatação que ela se nos dá no seio da variança histórica, restou-nos, por ora, estas pistas: o povo-rebanho da Roma Pagã, e o povo-criança da Roma Cristã. Governar seria nestes quadros: o conduzir do rebanho pelo Estado que pastoreia, e o mimar crianças pelo Grande-Pai estatal. Grosso modo é dizer das sociedades de soberania e das sociedades disciplinares tal como nos dispuseram as pesquisas de Foucault.

Insistamos um tanto mais na questão. Quem sabe a desdobramos em algumas metades. Como articular esta vontade de governo na construção da cidade, e na condução das gentes? A cartografia traçada pela lente de Foucault indica na constituição daquele que somos, nós os modernos, uma certa territorialização dos fluxos de migração - um fazer situar no espaço quadriculado e em atravessamento pelos registros do saber toda e qualquer multiplicidade. É já o mapa das instituições disciplinares que ele não se cansou de nos ofertar - escola, caserna, hospitais, prisões, e no seu dentro de luminosidade operatória, nós, este que se nos damos ao disparo epistemológico que, aquele instante, operou-se nos saberes acerca do homem. Nascimento do biopoder. Emergência do homem no espaço em que se diz dos saberes aquilo mesmo que estes engendram, discursos e práticas, dizeres e visibilidades. Nascimento do homem como devastação de fronteiras até então impossíveis aos olhares que perscrutam, a vontade de verdade. Nas bordas deste homem devassado, e não mais nos seus interiores de vísceras maculadas pelo 
saber que as corta, é que se depositará, então, o monstruoso, o irredutível outro, a incongruência abismada, o não-saber, o fatal erro, ou a experiência originária da loucura que, sem obra, escapa ao monólogo do que a aprisiona. Esta a experiência que é, a um só tempo, a do governo dos vivos e a da gestão da cidade disciplinada - fazer ver aquilo que se quer dobrar, dispor ao máximo da luz que dissipa o que for a noite da existência, o deserto do sem caminho. A cidade disciplinar é toda ela esta exaltação à luminosidade dos espaços públicos. Mesmo aqueles que derivam do que se impõe pela positividade do poder em sua criação de real, o que resta será o seu fazer incluir num regime ainda maior de luz e discurso: a histérica freudiana vasculhada desde os chistes, seu corpo-painel-somático da sintomatologia, a criança problemática sob a tutela da pedagogia ortopédica a dobrar-lhe o corpo desde as juntas - a posição ereta, o estômago arrancado à mesa, os perversos e os sodomitas aprisionados na vontade de seu desejo e este na miragem epistemológica que diz dele o que seria a sua verdade, íntima e fundamental. Para usar uma alegoria que diz da cidade disciplinar o seu formato, diríamos que ela é toda composta de dentros - como nódoas vascularizadas, plenas de ingresso, de entradas, portas a ligar a outras portas, discursos a encetar outros discursos e práticas, práticas a promover outros saberes e documentos instituídos, e outra vez mais, dentros sobre dentros, claustros em que se sai apenas pela morte - a que se sobreleva esta, a morte, ao lugar mesmo a que aspiram os românticos, sua liberdade última, a reserva íntima que é já toda o fora. De alguma forma, Kafka traça este sombreado de dentros intercomunicáveis donde não se sai senão morto, ou no reservado da loucura que é toda ela, nesta condição que se lhe dá, desterro, a loucura como desterro, o farrapo humano a que é tornada a processualidade esquizofrênica no labirinto de traumas alopáticos e de imperativos moralizantes que é o hospital - o corpo lânguido, extenuado, em fadi- ga de Gregor Samsa, a fazer dos braços não mais o movimento compulsivo das linhas de montagem, mas a disritmia em desequilíbrio que parece inumano, quem sabe vegetal, quem sabe animal, e viscoso este. Aquilo que se deixa esgotar no interior de um quarto sob risco da mostração pública, mas que por durar neste interior de aposento e clausura, acaba por desarrumar a família que se é e tem, e a montar o cenário mesmo de outra intervenção, ou a morte, ou o internamento ou a prisão. E ainda Kafka a dizer o que é o processo no seu interminável - o ir-e-vir das pernas atônitas de Josef K., a gratuidade dos jogos, o nonsense dos papéis e funções, o estar-se já no dentro sem voltas da condenação, e tudo é escritório e ao fundo a saída escamoteada, a parede falsa, a estante de livros giratória, a parede falsa, e eis que se tem a casa do magistrado, o conluio da secretária que é apenas pernas e peitos a confundir, a doença do advogado, o adiamento dos tribunais, os rostos em conformidade com as horas intermináveis em que se parece estar atado à monótona cadeia da existência. Tudo isto que fez Melville construir de forma ímpar o seu personagem escriturário, Bartleby. Este sendo o que não pôde Josef K., ou Gregor Samsa, qual seja, aquele que de dentro diz não poder estar de todo dentro, aquele que em sendo o escriturário a mover-se entre tarefas e horários e injunções apenas diz preferir não. Como sugere Gilles Deleuze: Bartleby é o homem da preferência, aquele que diz o que prefere quando não se trata de preferir e quando a linguagem costumeira parece dizer e implicar dizer de si as referências: de onde tu vens? Para onde tu vais? Com quem pensas que falas? O que sabes de ti? E a tudo, Bartleby diz preferir não, I would prefer not to. Nas palavras de Deleuze: "Pressionam-no a dizer sim ou não. Mas se ele dissesse não (cotejar, sair...), se ele dissesse sim (copiar), seria rapidamente vencido, considerado inútil, não sobreviveria. Só pode sobreviver volteando num suspense que mantém todo mundo a distância" (1997, p. 83). Bar- 
tleby é então aquele que estando dentro desconstrói, aquele que faz infiltrar ar, balões de oxigênio, no corpo entubado, e sua pequena saúde parece caminhar na direção mesma em que da grande saúde do Estado apenas podemos dizer a sua miséria de consumação, o seu faça-se internar - compelle entrare, o seu dispor à morte o que se lhe dá como alteridade incontornada, pois que volteia e volteia, em passos de balé - pegada quase nenhuma no solo de marcas, e aos olhares que vasculham as digitais, as referências outra vez, quem tu és, de onde vens, quem pensas ser, Bartleby é apenas homem "sem posses, sem propriedades, sem qualidades, sem particularidades: é liso demais para que nele se possa pendurar uma particularidade qualquer. Sem passado, sem futuro, é instantâneo" (ibid, p. 86). É aquele que deflagra a todo instante zonas de indiscernibilidade. Lá onde o poder se faz pura luminosidade, saberes e discursos, Bartleby suscita indeterminações. Este o seu outro lado, dizemos do poder, o lado de fora, a exterioridade desprovida de centro, de avesso e de direito. Adiantemos que o final da novela de Melville é a morte da personagem - porque a cidade se constrói sob a bravura (e a bravata) dos homens no cálculo do que é a recusa, a vontade de negação. E o que estiver fora, e o que falar desde o fora, e o que supor uma alteridade radical é justo aquilo que se deve conjurar para fazer prevalecer a justa medida, expressão do normativo. Bartleby está fora, logo e sempre, da cidade disciplinada. Seu espaço é o deserto em que a noite se mostra eivada do que for neblina, desassossego, inquietude, ventos gelados a tomar o corpo, uivos de lobos e do que for o fabulário da teratologia. Para ele, a cidade se fechará. Na construção da muralha da China, que nas palavras de Kafka, é a defesa da cidade contra os povos nômades, aqueles que vêm do Norte (e o Norte é todo lugar que é fora da cidade...), aqueles que vêm do Norte, os nórdicos, os bárbaros (pois quem não for geômetra não entra...), aqueles que vêm do Norte, os hereges (que saídos da cidade acaba- ram por construir os mosteiros...), aquele que vem do Norte, Bartleby. A cidade se regozija no dentro da muralha, e a China em sua imensidão estará fadada a não se imiscuir com o que a desordenasse, e outra vez, é Kafka a dizer da muralha a sua função: a proteção contra os nórdicos, mas qual e quem, se eles nunca chegam ou chegaram, e se nós nunca ousamos ir até onde eles supostamente se colocam, e então a muralha é o que parece conter o que sequer se dá. Esta a sua função. A da contenção. E a do demarcamento. A cidade disciplinada ancora-se numa geopolítica rigorosa. No entroncamento destas partes - o registro dos dentros, sua inscrição numa ritmia ordenada e regular, a demarcação das fronteiras, a conjuração dos monstros que são os outros, é que se fundaria a cidade moderna, uma sua sedentariedade urbana.

E eis que outra vez nos deslocamos. Estamos em 2054. Habitamos a terra sem terra que é o fabulário de Spielberg. Nos perguntamos pela cidade que há no filme: qual a cidade? Sabemos que se trata de Washington. Mas isto pelos créditos, não pela paisagem que se reconhece. Dela sabemos que não há crimes, que os assassinatos foram escasseando, que a violência urbana fora contida. Mas quede a horda de gentes em conluio no espaço público? O ir-e-vir em esbarrões fortuitos no centro da cidade, ou os jogos de criança a inventar o mundo lúdico nas praças, ou o comércio no seu fazer da troca de mão a mão, e que circulam fluxos de mercadorias \& de capital \& de suores \& de esperma, o corpo investido do serviço, ou o corpo que é o serviço mesmo, o que se troca na erótica transversalizada pelo lucro, e quede a linguagem no enleio deste fazimento que é pura troca e fixidez, a estrutura que é também o que se desmonta, o acontecimento a se inscrever nos interstícios dos saberes e dos costumes, Bartleby, Gregor Samsa, Josef K., ou outros os tipos, alguns fascistas - o alienista a depositar no relicário que é a Casa Verde toda a tipologia de estranhos de Machado de Assis, ou outro, os tipos vis descritos 
por Primo Levi, ou outro, o homem que foi ser gauche na vida, o funcionário público que somos, quede isto no interior do que seja a cidade de Spielberg? Pois parece que não há cidade senão o passamento frenético e inconcluso de carros que descem edifícios e que descem estradas que parecem edifícios e que seguem sabe-se lá para qual lugar, ou que se circula apenas nos interiores dos shoppings em que se compra aquilo que diz apenas para nós e para mais ninguém, estágio hiperdesenvolto do que é a individuação, a identificação retiniana, a publicidade que fala para este um e apenas a ele, olá a ti, hello John Anderton, as lojas da Gap, o vestuário do conforme, o tempo suspenso ao pensamento que parece exigir a duração, o tempo da conexão hiper-rápida, a imagem líquida, digitalizada, fluida a barganhar o que se oferta a ti e apenas a ti, em silêncio sepulcral, ou na tagarelice atônita e sincronizada que fala a todos e a cada um ao mesmo tempo sem que haja gestalt possível, sem que exista, ou persista qualquer coisa que não seja acionada por um input-output, ligar e zapear, ou desligarse em face do ecrã que paralisa, ou que impõe ao mais frenético dos ritmos, o ir-e-vir descarnado, virtualizado, desterritorializado do corpo-húmus, a manipular cartões de crédito como quem empunha bandeiras, e canta marchinhas que já não se ouve. Mas quede a cidade do filme? Uma cidade sem interior, e sem arrabaldes, mas há mesmo cidade? A malha viária, a polícia aduaneira, o deserto beirando a cidade como quando se está no Oriente, a pergunta que insiste em não se calar: quede a cidade? Em uma das cenas do filme de Spielberg, o personagem vivido por Tom Cruise, John Anderton, consegue focar o lugar de uma sua intervenção por se dar a ver na tela líquida em que se dispõe a sua demiurgia uma pracinha com gira-gira e chafariz e escorregador e balancinho, e ele então afirma: "Apenas existem três" na cidade que é toda metrópole. Aqui os dentros são outros do que dizíamos da cidade disciplinada. Também sempre se está dentro - mas tais dentros são fluidos, móveis, modulagem antes de moldes, e tudo isto aquoso, esgarçável, plástico - os carros, os corpos, os rostos, os shoppings. Se na cidade disciplinada, os dentros retardavam as misturas, continham os corpos em relações de pertença, a tua casa, a tua referência, as tuas digitais, com quem tu andas, quantos os filhos, aqui, a cidade é feita de lugares sem pertença, de lugares sem lugar, de velocidade sem duração, e de órgãos que se manipulam de forma indiscriminada, a face que se modifica na ingestão de substâncias autodeformantes, saiba como usar, faça você mesmo a sua plástica, o corpo anoréxico, a bulimia, o sarado ascético em devoção aos diet/light/natureba, os olhos, a retina é o que distingue o traço, perfil de consumidor, isto a interioridade, o perfil de consumidor que é o terminal do que for negócio, input/output, pela retina o traço identitário, mas tão logo é que se trocam as retinas em lugares inóspitos e sob a sordidez de quem opera, de quem trabalha - pois que parece que também o trabalho é o desaparecido. Quede as hordas de trabalho, ou os grevistas em passeata, a cidade como Ágora política e o demos na sua movença de fazimentos e construção, quede isto, mas qual e onde, na cidade do sem gente são as câmeras o que cresce em número a se espraiar por toda parte. Milagre da multiplicação do olhar sem filamento de membrana ocular. E tudo à espreita, pois que se está à espreita continuamente, de forma ubíqua, em assalto ao tempo, o seqüestrado este mesmo, o tempo do fazer, o tempo do acontecimento, o tempo da errância e dos deslocamentos, fluxos migratórios, destituição e recomposição de partes e todo, a cidade e suas saídas, seu fora, o deserto a lhe beirar e lhe impor seus limites, e a gente que vem do fora, outros compostos subjetivos, a Grace de Dogville no filme de Lars Von Trier, todo e qualquer nomadismo, isto o seqüestrado, a rebeldia, ou o seguir em frente, o rebelar-se, ou a adequação contumaz, o agenciar linhas de fuga, vazantes entre os córregos e diques, e então eis que o seqüestrado é o acontecer do 
acontecimento na gestão imperiosa do futuro. Câmeras estão em todas as partes. Apenas escapam à sua eficácia os becos em que se trafica o que for - clarity é nome da droga sintética, mas também olhos, também informações, também abandono. Parece que é a rua esta zona devastada - o espaço em que a cidade se faz ver como ruína \& resíduo. A cidade que há no filme parece ser o prédio de moradores comuns, que somos, ou éramos, nós, e não eles, e que então é, agora, a ruína, luz cortada, infiltração por todo lado, briga de casal à antiga, trepada de casal à antiga, embriaguez comum à antiga, e solidão, alimento apodrecendo na geladeira que não dá vazão, ratos espalhados por toda parte, e entre tudo isto, o homem, o bicho envolto em jornal, o que se abandona à própria sorte no corpo do Estado-minimal-dromocrático ${ }^{2}$ que sequer forja-se outro do que o espaço do publicitário e de vetor dos enunciados de segurança. Esta a cidade do filme a se proteger sobremaneira do que lhe diz respeito - trata-se de cidadãos? Outra vez, e em eco: é de cidadãos o que se trata nos interiores da cidade que é pura $\boldsymbol{e x}$-posição, ela mesma e toda, a cidade de imagens, a imagem da cidade - a cidade a caber na tela de mediação. Ouçamos as palavras de Paul Virilio, pensador e urbanista francês em seu livro A Arte do Motor: "Depois de trinta anos de desempenhos audiovisuais, o complexo informacional repousa sobre uma nova equação: um homem = um gueto. O rádio e a televisão só se dirigem à massa anômica que eles próprios contribuíram para formar, pântano social inextrincável no qual os atores sobrevivem tão bem quanto mal na solidão múltipla, marginais, divorciados, desempregados, membros de minorias étnicas, sexuais ou sanitárias, filhos de famílias monoparentais entregues a si próprios" (1996, p. 23 - grifo do autor).

Minority Report fala desde o ocaso da cidade desconstruída, a cidade disciplinada. Resta uma montagem outra do que era o urbano. Ousamos dizer que esta cidade não foi cartografada pelo instrumental teó- rico foucaulteano. O presente que ela acena, ainda que não tão logo, mas já um tanto aqui, é inteiramente outro das cidadelas da retenção no tempo e no espaço - as velhas instituições de seqüestro, as instituições fechadas e totais, a conter o corpo e a ordenálo. Porém, se podemos tecer esta descontinuidade entre tais cartografias, se podemos indicar claramente as incompatibilidades entre elas, a cidade disciplinada e a cidade pós-moderna/futurista, lembramos que começamos este ensaio flertando com uma afirmação, aquele instante, algo inadvertida: a de que experimentamos alguma quase-continuidade entre o presente de que dispomos, a sociedade de controle de que falou Gilles Deleuze, e de que falam Michael Hardt, Antônio Negri, Giorgio Agamben, e este fabulário desterritorializado aludido por Steven Spielberg. Claro está que tal quase-continuidade diz respeito à razão política impressa na vontade de governo, naquilo que se entende por governo quando se trata de governar. E aqui a pista do comum que as agencia sobre um mesmo plano é a do abandono do que era a geopolítica, pelo advento de uma cronopolítica. Uma política da velocidade, uma politização do tempo. Não mais a demarcação do espaço e das gentes em seus interiores, mas o esgarçar de todo e qualquer interior, e a inclusão ou exclusão na velocidade como condição mesma daquilo que se forja ser, por exemplo, policeman, ou apenas man, policial ou perseguido, condutor ou interceptado, as gentes, os usuários, os consumidores todos, que somos. Como sugere Paul Virilio, os ritos de passagem não são mais intermitentes, mas imanentes. Porque sempre se está preso na passagem, na excelência da condição de passageiro porque passa e não deixa de passar, porque segue e não fixa, porque deflagra e não retém. Menos do que habitantes, são estes os usuários da cidade que é passagem e passamento, outros do que residentes privilegiados, são antes "os interlocutores em trânsito permanente" (1993, p. 08).

Na cidade de Spielberg, em que não 
há espaço público, o lugar do acontecimento é a tela antecipatória que se dá a ver no Departamento do Pré-crime, máquina de visão do futuro, os pré-cogs, vislumbram estes de sua cama aquática em que estão presos e sem movimento, o enredar antecipado do que não se deu, a teia ou a trama dos fatos no inventário do impossível, na urdidura do real em desfazimento, o futuro a se antecipar na forma de imagens lançadas à tela de observação policial, tela líquida, tela total, em que o futuro se faz ver para não se fazer valer - e ali o futuro é sempre o mesmo, é o que assalta, é o flagelo, é o mover das pessoas na direção do que as incriminará - menos, quem o saberia dizer, pelo que fazem, ou viriam a fazer, e mais por um ousar fazer, um fazer qualquer, um inscrever-se no tempo quando a duração é o que está em suspenso. E então o crime que não se deixa vingar. A intervenção militar em aborto ao acontecer do que for, pois que tudo é o que se dá a ver, e o real todo ele sendo o que se faria acontecer para reafirmar a infalibilidade do controle, a gestão do futuro - "uma trucagem da realidade, uma encenação com mudanças de cenários, disfarces, maquinárias, deus ex machina..." (VIRILIO, 1996, p.33). Para terminar, poderíamos dizer que se trata, na alegoria tecnológica de que fala o filme de Spielberg, de uma câmera de descompressão do real - espécie de máquina reversão do tempo, ou de uma sua anulação, o futuro tragado desde o presente total, rewind após rewind, os dedos sem digitais nas teclas, ou na dança dos gestos sobre a tela líquida, e dali o que surge parece não ser outro do que o cenário neoplatônico a prefigurar o real no dentro sem fundo e tempo, pois que firmado em torno do tempo real, das ilhas de edição •

\section{Notas}

1 Como afirma Giorgio Agamben em entrevista ao Caderno Prosa \&Verso, dia 04 de dezembro de 2004: "Uma democracia só pode funcionar se 0 seu fundamento - 0 povo enquanto corpo político - está sempre ativo e vivo. Ora, o que se passa com o biopoder é precisamente que 0 povo enquanto sujeito político desaparece em proveito da população, que é um conceito demográfico-biológico e não político. Em nenhum lugar hoje nós encontramos povos, mas unicamente populações, que se definem pelas suas necessidades econômicas, biológicas, de saúde, etc. É isso que os regimes totalitários tinham tão bem compreendido (...) e é evidente que aqui democracia e totalitarismo entram numa zona de indistinção".

2 Se o cúmulo da velocidade é o extermínio do espaço, poderíamos dizer, seguindo os passos de Virilio, que "a inércia da cidade do futuro não é a inércia da imobilidade, mas a ditadura do movimento" (1984, p. 67), ou ainda, como ele afirma noutro instante, "a liberdade não está ameaçada por uma proibição como na época de Foucault, em que se fechavam as pessoas numa prisão para que elas não pudessem mover-se. Agora, fecham-se na rapidez e na inanidade de qualquer deslocação" (1996, p. 57).

\section{Referências}

DELEUZE, G. Bartleby, ou a fórmula. In: Crítica e Clínica. São Paulo: Editora 34, 1997 (p.80-103).

VEYNE, P. Foucault revoluciona a história. In: Como se escreve a história. Brasília: Editora da UnB, 1995 (p.149-181).

VIRILIO, P. Guerra Pura. São Paulo: Brasiliense, 1984.

. O Espaço Crítico. Rio de Janeiro: Editora 34, 1993.

A Arte do Motor. São Paulo: Estação Liberdade, 1996.

Cybermonde - La politique du pire. Entretien avec Philippe

Petit. Paris: Les éditions Textuel, 1996. 